\title{
Correction to: Schumpeter's business cycle theory and the diversification argument
}

\author{
Vipin P. Veetil
}

Published online: 12 January 2021

(c) Japan Association for Evolutionary Economics 2021

\section{Correction to: Evolutionary and Institutional Economics Review https://doi.org/10.1007/s40844-020-00190-1}

In the original publication of the article, the following reference "Alan K (2016) Networks: a paradigm shift for economics? The Oxford handbook of the economics of networks. Oxford University Press, Oxford, pp 13-46" was published incorrectly.

The correct reference should read as follows "Kirman A (2016) Networks: a paradigm shift for economics? The Oxford handbook of the economics of networks. Oxford University Press, Oxford, pp 13-46".

Publisher's Note Springer Nature remains neutral with regard to jurisdictional claims in published maps and institutional affiliations.

The original article can be found online at https://doi.org/10.1007/s40844-020-00190-1.

Vipin P. Veetil

vipin.veetil@gmail.com

1 Department of Humanities and Social Sciences, Indian Institute of Technology Madras, Chennai 600036, India 